\title{
Lessons Learned from Twelve Years of Partnered Tobacco Cessation Research in the Dominican Republic
}

\author{
Deborah J. Ossip, ${ }^{1}$ Sergio Díaz, ${ }^{2}$ Zahira Quiñones, ${ }^{2}$ Scott McIntosh, ${ }^{1}$ Ann Dozier, ${ }^{1}$ Nancy Chin, ${ }^{1}$ \\ Emily Weber, ${ }^{1}$ Heather Holderness, ${ }^{3}$ Essie Torres, ${ }^{4}$ Arisleyda Bautista, ${ }^{5}$ Jóse Javier Sánchez, ${ }^{2}$ \\ Esteban Avendaño, ${ }^{6}$ Timothy De Ver Dye, ${ }^{7}$ Paul McDonald, ${ }^{8}$ and Eduardo Bianco ${ }^{9}$ \\ ${ }^{1}$ Department of Public Health Sciences, University of Rochester Medical Center, Rochester, New York, USA \\ ${ }^{2}$ Department of Medicine, Pontificia Universidad Católica Madre y Maestra, Santiago, Dominican Republic \\ ${ }^{3}$ Department of Pediatrics, University of Rochester Medical Center, Rochester, New York, USA \\ ${ }^{4}$ Department of Health Education and Promotion, East Carolina University, Greenville, North Carolina, USA \\ ${ }^{5}$ Centro de Atención Primaria Juan XXIII, Santiago, Dominican Republic \\ ${ }^{6}$ School of Public Health, Universidad de Ciencias Médicas, San José, Costa Rica \\ 7 Department of Obstetrics and Gynecology, University of Rochester Medical Center, Rochester, New York, USA \\ ${ }^{8}$ College of Health, Massey University, Auckland, New Zealand, and School of Public Health and Health Systems, University of \\ Waterloo, Waterloo, Canada \\ ${ }^{9}$ Framework Convention Alliance (FCA), and Centro de Investigación para la Epidemia de Tabaquismo (CIET Uruguay), \\ Montevideo, Uruguay
}

\begin{abstract}
E ngaging partners for tobacco control within low and middle income countries (LMICs) at early stages of tobacco control presents both challenges and opportunities in the global effort to avert the one billion premature tobacco caused deaths projected for this century. The Dominican Republic (DR) is one such early stage country. The current paper reports on lessons learned from 12 years of partnered United States (US)-DR tobacco cessation research conducted through two NIH trials (Proyecto Doble T, PDT1 and 2). The projects began with a grassroots approach of working with interested communities to develop and test interventions for cessation and secondhand smoke reduction that could benefit the communities, while concurrently building local capacity and providing resources, data, and models of implementation that could be used to ripple upward to expand partnerships and tobacco intervention efforts nationally. Lessons learned are discussed in four key areas: partnering for research, logistical issues in setting up the research project, disseminating and national networking, and mentoring. Effectively addressing the global tobacco epidemic will require sustained focus on supporting LMIC infrastructures for tobacco control, drawing on lessons learned across partnered trials such as those reported here, to provide feasible and innovative approaches for addressing this modifiable public health crisis.
\end{abstract}

\section{Introduction}

Tobacco use is projected to result in 1 billion premature deaths globally in this century, with most occurring in low- and middle-income countries (LMICs; Jha, 2009; WHO, 2011). Over 180 countries are parties to the WHO Framework Convention on Tobacco Control (FCTC), and $40 \%$ have implemented at least one associated MPOWER (Monitor, Protect, Offer help, Warn, Enforce, Raise taxes) measure at the highest level of achievement (WHO, 2015). Nevertheless, global declines in tobacco use prevalence remain below targets and considerable disparities exist among countries (Bilano et al., 2015). Persistent actions are needed to avert this pandemic. This need particularly extends to countries at early stages of tobacco control, and to countries with currently low tobacco use prevalence rates where effective tobacco control can avert an upward trajectory (Bilano et al., 2015; Britton, 2015).

Engaging partners for tobacco control within early stage LMICs presents both challenges and opportunities (Ossip, 2013). The DR is an example of such an LMIC. At the initiation of our projects in 2002, there was no national tobacco surveillance system, little published research on 
Table 1

Examples of global participatory research/CBPR principles incorporated into PDT

\begin{tabular}{|c|c|}
\hline Principle & Implementation in PDT1 and PDT2 \\
\hline $\begin{array}{l}\text { Involve local community investigators, working groups, } \\
\text { boards as research partners }\end{array}$ & $\begin{array}{l}\text { - Local CTC site managers and management boards identified community members to } \\
\text { serve as data collectors } \\
\text { - Community partners/working groups served as advisors for intervention development } \\
\text { and interpretation of results }\end{array}$ \\
\hline Engage local investigators as authors/co-authors & $\begin{array}{l}\text { - US and DR team members serve as co-authors on publications and presentations } \\
\text { - All team members provided trainings and scientific presentations }\end{array}$ \\
\hline $\begin{array}{l}\text { Develop and maintain trust through long-term } \\
\text { commitment }\end{array}$ & $\begin{array}{l}\text { - The } 12+\text { year time frame provided a long-term presence } \\
\text { - Dissemination activities linked communities with national activities to promote } \\
\text { sustainability } \\
\text { - The current MundoComm grant continues engagement of partners }\end{array}$ \\
\hline $\begin{array}{l}\text { Provide funding directly to community-based } \\
\text { organizations; hire community members }\end{array}$ & $\begin{array}{l}\text { - PDT hired and trained local community members as site coordinators, tobacco control } \\
\text { specialists, and data collectors } \\
\text { - Local CTCs served as coordinating centers } \\
\text { - Funding was provided to community-based staff and CTCs }\end{array}$ \\
\hline $\begin{array}{l}\text { Provide training opportunities for members of } \\
\text { traditionally marginalized communities }\end{array}$ & $\begin{array}{l}\text { - All participating communities were economically disadvantaged } \\
\text { - PDT provided training to local staff as well as to health care providers in all } \\
\text { communities }\end{array}$ \\
\hline $\begin{array}{l}\text { Engage community members in analysis and } \\
\text { interpretation of results }\end{array}$ & $\begin{array}{l}\text { - Results were presented to local teams for input in interpretation, and to communities in } \\
\text { interactive talks by research team members for feedback }\end{array}$ \\
\hline
\end{tabular}

tobacco use, no active political or public health infrastructures for tobacco control, no national public health awareness campaigns regarding tobacco risks, and no national (and few or no local) resources for cessation. The few national regulations were not well known to the public and unevenly enforced (Dozier et al., 2006). In addition, as of 2015, the DR remained the only country in the Latin America and Caribbean (LAC) region that had not yet even signed on to the FCTC.

Although tobacco control was lacking, the DR had a network of Community Technology Centers (CTCs), a national infrastructure through the DR Office of the First Lady and later the Office of the Vice President. US team members had previously been involved in development of these centres. Placed in economically disadvantaged communities and coordinated by local community management boards, CTCs provide technological resources (e.g., electricity, telephones, computers, internet, radio stations, and technology classes) to underserved communities and were well positioned to serve as bases for our project operations.

We report on over a decade of tobacco cessation research in the DR, conducted through two NIH-funded trials. The goal is to share lessons learned specific to research on tobacco cessation (FCTC Article 14; see Raw et al., 2009) as a case example that can provide practical guidance to project teams in other LMICs, with the ultimate goal of empowering grassroots as well as national teams in disseminating, implementing, and evaluating evidence based tobacco interventions.

This manuscript is organized into a description of the $\mathrm{DR}$, rationale/description of the research, lessons learned for establishing the infrastructure for community partnered research around tobacco use, future directions, and conclusions.

\section{DR Country Description}

The DR is located on the Caribbean island of Hispaniola (shared with Haiti), has a population of about 10 million, and is divided into 31 regions plus the National District where Sango Domingo (the capital) is located (PAHO, 2012). The population is $73 \%$ mixed races, $95 \%$ are Roman Catholic, and 79\% live in urban areas (CIA, 2015). About $76 \%$ have at least six years of education, and $10.7 \%$ are illiterate (PAHO, 2012). The DR moved from classification as a lower-middle income country (World Bank Group, 2001) to an upper-middle income country (World Bank Group, 2015), though income disparities exist and $41.1 \%$ of the population lives below the poverty line (CIA, 2015). The DR produces tobacco, and is 11 th among countries globally devoting $\geq 0.36 \%$ arable lands to tobacco. Daily adult tobacco use ranges from $14.5 \%-15.3 \%$ among men and 9.6\%-10.4\% among women (Eriksen, Mackay, Schluger, Gomeshtapeh, \& Drope, 2015); we have reported total (daily + nondaily) tobacco use prevalence of $27.2 \%$ 
for men and $18.2 \%$ for women, with very few ex-users $(5.62 \%)$ in six economically disadvantaged DR communities (Ossip-Klein et al., 2008).

\section{Research Rationale/Description}

As described above, the DR was at an early stage of tobacco control (Dozier et al., 2006), and the lack of political will and supportive infrastructures for policy implementation consistent with the FCTC made a national focus premature. We, therefore, opted to begin with a grassroots approach, partnering with investigators and individual communities for randomized controlled trials targeting tobacco use. This approach also addressed the urgent global need to address tobacco dependence treatment (Raw, Mackay, \& Reddy, 2016). These trials provided opportunities for jointly developing and testing interventions as well as building local capacity for data collection and intervention delivery. As materials and expertise were developed, teams disseminated these resources and findings more broadly to regional, provincial, and national groups, hypothesizing that receptivity of these groups would be enhanced by seeing tangible examples of resources and models of in-country tobacco use interventions.

Projects were funded by two NIH grants (Fogarty International Center, National Cancer Institute), beginning in 2002. The projects were entitled 'Proyecto Doble T'(Project Double T; PDT), referring to Tobacco use and Technology centers. Both projects used community based participatory research models (Israel, Schulz, Parker, \& Becker, 2001; Riley et al., 2001; CTSA Consortium, 2011) to guide partnerships with investigators, working groups, and communities (see Table 1 for examples).

The project was conducted by a multidisciplinary team of investigators from the US and DR, including specialists in psychology, anthropology, nursing, epidemiology, statistics and public health (United States (US) team), and medicine (DR team). Guidance was provided by an International Advisory Committee, with tobacco control leaders from Uruguay, Canada, Costa Rica, and the US. Local CTC coordinators generally served as site managers and tobacco cessation specialists (TCS) for PDT1 and 2. CTC coordinators and management boards assisted investigators in identifying community members to engage as data collectors.

For both projects, communities with CTCs that were actively providing programs were matched on size, geographic location (small urban, peri-urban - small urban structure in remote location, and rural), and other community characteristics, and invited to participate. Project flow is presented in Table 2. Communities were randomized within pairs to intervention or control, using a lagged treatment design, with all communities receiving intervention after a one year comparison period. Projects began with a qualitative Rapid Assessment Process (RAP, Beebe, 1995), with mixed DR-US teams assessing the sociocul-
Table 2

PDT1 and PDT2 project flow

\begin{tabular}{|c|c|c|}
\hline Activity & PDT1 & PDT2 \\
\hline $\begin{array}{l}\text { Communities matched and randomized } \\
\text { to intervention vs. control (lagged } \\
\text { treatment design) }\end{array}$ & 6 & $7^{1}$ \\
\hline \multicolumn{3}{|l|}{ Baseline } \\
\hline Qualitative Assessment (RAP) & $\mathrm{x}$ & $\mathrm{x}$ \\
\hline $\begin{array}{l}\text { Surveys: Surveillance, Community, } \\
\text { Tobacco Users, Healthcare } \\
\text { Providers (HCPs) }\end{array}$ & $\mathrm{x}$ & $x$ \\
\hline \multicolumn{3}{|l|}{$\begin{array}{l}\text { Intervention: Intervention vs. control } \\
\text { communities (1 year) }\end{array}$} \\
\hline Awareness raising & $x$ & $x$ \\
\hline Tobacco cessation & $\mathrm{x}$ & $\mathrm{x}$ \\
\hline Secondhand smoke reduction & & $\mathrm{x}$ \\
\hline \multicolumn{3}{|l|}{ Follow-up 1} \\
\hline Qualitative assessment (RAP) & $\mathrm{x}$ & \\
\hline $\begin{array}{l}\text { Surveys: Surveillance, community, } \\
\text { tobacco users, HCPs }\end{array}$ & $\mathrm{x}$ & $x$ \\
\hline Intervention: All communities (1 year) & $\mathrm{x}$ & $x$ \\
\hline \multicolumn{3}{|l|}{ Follow-up 2} \\
\hline $\begin{array}{l}\text { Surveys: Surveillance, community, } \\
\text { tobacco users, HCPs }\end{array}$ & $\mathrm{x}$ & $x$ \\
\hline \multicolumn{3}{|l|}{ Networking (all project years) } \\
\hline Informal & $\mathrm{x}$ & \\
\hline Formal national networking team & & $\mathrm{x}$ \\
\hline
\end{tabular}

${ }^{1} 8$ communities were originally randomized; one was dropped due to data falsification (See 'Implementing quality assurance procedures').

tural landscape of tobacco use during 2-3 days visits to each community (Chin et al. in press; Dozier et al., 2006, 2009). Results informed subsequent survey and intervention development. The first trial, PDT1, examined the effectiveness of tobacco cessation interventions in six economically disadvantaged communities. PDT2 expanded the focus to include secondhand smoke exposure reduction in seven economically disadvantaged communities (four original and three new communities). Based on the prior literature, results of the RAPs and surveys, and community input, interventions across trials included awareness raising (e.g., health fairs to launch PDT, healthcare provider trainings, community talks (charlas), student marches, locally produced radio public service announcements (PSAs), radio talk shows, posters, brochures) followed by cessation interventions (e.g., cessation classes in person and on radio, 1:1 counselling, computer assisted cessation resources, healthcare provider interventions). Quitlines and pharmacotherapy were not possible because neither widespread telephone access nor cessation medications were available. Measures included baseline and follow-up household surveillance of demographics and tobacco use/exposure; community surveys of tobacco 
knowledge, attitudes, behaviours, and exposures; tobacco user surveys to monitor cessation; and healthcare provider surveys of knowledge, attitudes, and practices. A PDT core community team, consisting of a DR co-investigator and her coordinator, headed community-based assessments and interventions.

Concurrently with community activities, national networking began informally in PDT1 to develop linkages to professional medical societies, government groups, NGOs, and media sources interested in tobacco control. This process was formalized through a PDT2 core national networking team led by the DR site principal investigator and his coordinator. Examples of resulting activities include national training workshops for regional and provincial public health workers and school counsellors through the Health- and Education Ministries; multiple in-country media events on radio, television, and newspaper; partnered events with NGOs around tobacco use; infusion of tobacco control content in the medical curriculum of a major university; and presentation of tobacco intervention workshops and scientific papers at international and in-country conferences.

We continue to report findings from PDT studies elsewhere (e.g., Chin et al., in press; Dozier et al., 2006, 2009, 2014; Lando et al., 2010; McIntosh et al., 2008; Ossip, 2013; Ossip, et al., 2015; Prucha et al., 2015; Torres et al., 2011, 2104; Wipfli et al., 2008). The current paper will report on lessons learned from implementing this US-DR partnered research.

\section{Establishing an Infrastructure for Tobacco Cessation Research: Lessons Learned}

Lessons learned are identified in the following four areas: partnering for research, setting up the research project, disseminating and networking, and mentoring.

\section{Partnering for Research}

This section discusses lessons learned in forming the partnered DR-US team of investigators and in engaging communities as partners.

Use an existing infrastructure. Critical to the feasibility of developing a tobacco intervention project in a country with no history of such work was the ability to tap into the existing infrastructure of CTCs with whom some of our investigators had already worked. Although this prior work was on a different topic, the established community and local investigator relationships, and the common base of CTCs in each community greatly facilitated the development of this joint research initiative.

Take time to build trust. Building trust involved recognizing each side's expertise, developing processes for joint decision making (decisions need to be acceptable to both sides), and making a long-term commitment to the project. Decision sharing extended beyond the DR-
US investigator team to the core network and community teams, local community teams, community leaders, and other combinations of project groups working together within a CBPR context. Our experience is that this trustbased partnership takes approximately one year to gel. Operational strategies for facilitating communication, shared ownership and trust included: (1) face-to-face meetings in the US and DR, held at least twice/year, to jointly create realistic working plans, strengthen team commitment, and connect with other in-country partners; (2) weekly conference calls to follow progress, tackle unexpected challenges, and uncover new ideas and opportunities as PDT progressed; (3) multi-authored publications and scientific presentations at local, national, and international conferences.

Engage Communities as Partners. CTC leadership and coordinators were essential in providing local community expertise, assistance in identifying community members to participate in the RAPs and to serve as data collectors, and input for interpreting project results. Engagement also included: (1) providing presentations to community leaders and community members describing the project and soliciting ideas; (2) presenting local survey results to the communities for input prior to intervention launch, asking such questions as, 'Do these results look like what you would expect; if not, why do you think they are different?'; and (3) based on CBPR principles (Israel et al., 2001), providing monthly payment for CTC use, hiring and training local site managers, smoking cessation specialists and data collectors; and (4) incorporating community ideas to tailor evidence-based interventions to DR communities. This likely enhanced intervention ownership in the communities, and provided creative approaches for implementing core components. Examples of locally generated approaches shared across communities included dramatic enactments, dances, personal stories, Facebook pages, and locally created PSAs (cuñas).

\section{Setting up the Research Project}

This section discusses lessons learned regarding logistical issues of Institutional Review Boards, formative research, survey development, and trainings for local data collectors and TCSs.

Obtain All Required Institutional Review Board (IRB) Approvals. We have described IRB complexities for USLMIC research elsewhere (McIntosh et al., 2008), and will note key lessons learned here. First, especially for teams without prior experience with their IRBs for global research, it is valuable to have face to face meetings with IRB representatives to review study protocols, clarify proper steps, and problem solve challenging issues. Second, multiple IRBs may be required to ensure that all LMICmandated and US-approved IRBs approve the project. In the DR, the nationally mandated IRB was not on the US Office of Human Subjects Protection approved list, so dual DR IRB review was required. The review process was 
often lengthy and carried a fee, and approval from all DRand US IRBs was required before trial initiation. Thus, investigators need to allow ample time and budget for IRB review. Finally, investigators need to recognize that IRB regulations may vary across countries. For example, in the DR, paying survey participants is considered coercive; however, small appreciation gifts may be given after survey completion if participants are not informed of this in advance.

Conduct Formative Research. As described above (see Research Rationale/Description), projects began with qualitative research (RAPs). From a research standpoint, RAPs were critical to understanding the communities, the cultural context of tobacco use, and practical issues including what words were used for various forms of tobacco. RAPs results shaped survey and intervention development and implementation. The process of conducting the RAPs also facilitated relationship building among RAP team members, and with community CTC site managers and community members who saw their input reflected in project implementation.

Survey development is a joint process. Face to face meetings with DR-US investigators and their coordinators were used for survey development prior to each launch. Grids of domains to be assessed were developed and then populated by items from existing surveys, results of the RAPs, and new items as needed. Lessons were learned in several areas:

a) DR team expertise guided cultural tailoring of items. For example, the DR team pointed out that Likert scales (standard for several items) were unfamiliar to community members. This was resolved based on DR team experience, by including graphics of faces corresponding to scales (see Figure 1 example). Multiple pretesting, including by data collectors during training, as well as pilot testing in a comparable community, provided further refinement.

b) Annotating archival versions of the surveys with sources of items facilitated comparisons with other studies and reporting of any changes from original wording.

c) Methodology needed to be adapted to local realities. One logistical challenge was how to randomly select households for surveillance in communities for which there were neither maps nor home addresses, and how to randomly select household members within homes for the community survey. The former was resolved by asking CTC site managers to create hand drawn maps (croquis) with houses numbered so that the US team could generate randomly ordered lists of homes for data collectors to approach. The random selection issue within households was solved by the DR team through 'ping pong randomization.' Data collectors were given bags with numbered ping pong balls. During surveillance, data collectors created a numbered list of household members. After surveillance, data collectors or interviewees extracted a ping pong ball and the adult household member whose number corresponded to ping pong ball number was invited to participate in the community survey. Ping pong balls were lightweight to carry, waterproof, and creatively facilitated random selection.

Use local models for training. Training and oversight for site managers and data collectors across multiple communities were key. More detail on training is provided elsewhere (Ossip et al., 2015; Ossip-Klein et al., 2008); lessons learned are presented here:

a) Implementing a two-stage approach facilitated team building and skill mastery. For stage 1 , data collectors and site managers attended a central $2 \frac{1}{2}-3$ day face to face interactive training prior to each survey round. This enabled teams to bond as a group, view themselves as part of a larger project team, and share experiences of what worked, particularly in unexpected situations. For stage 2, immediately prior to launch, the DR core community team provided on-site refresher training and assisted site managers in supervising the first 1-2 days of survey administration.

b) Conducting weekly site visits and between-visit phone contacts with site managers by the DR core community team maintained momentum during data collection.

c) Implementing quality assurance procedures was critical, as was refining these procedures as challenges arose. First, we worked to make it easy for data collectors to do their jobs correctly. Data collectors (and site managers) were provided with Standard Operating Procedures/Manuals and one page 'Daily Procedures' checklists of to carry with them, organizers and PDT project bags for carrying materials, umbrellas, pens, bags with ping pong balls for random selection, colour coded surveys, random household lists with disposition fields for each household, and the same household gifts given to participants. Second, site managers provided daily supervision of data collectors, reviewed all survey forms for completeness, and provided feedback to data collectors on errors, with repeat household visits as needed. Third, the DR core community team reviewed surveys during weekly visits and re-visited households to check the accuracy of surveys that appeared unusual. Nevertheless, several instances of data falsification were detected, including one that required dropping an original 8th community from the PDT2 trial. This resulted in lessons learned to improve quality assurance procedures. A central face to face re-training was immediately held with all data collectors and site managers in remaining communities, which included interactive vignettes demonstrating falsification vs. ethical procedures. This was followed by ongoing random household checks by the core community team during 


\section{Spanish Version}

[MUESTRA LA SEGUNDA LÍNEA DE LAS CARITAS]

5.3 "Usando una nueva escala de I-5, donde ahora I significa que no mejora y 5 significa que mejora extremadamente, ¿qué tanto piensa usted que la salud de un fumador se mejoraría si dejara de fumar?"

[MARQUE LA RESPUESTA CON UNA " $X$ ” EN ESTA FILA DE CASILLAS]

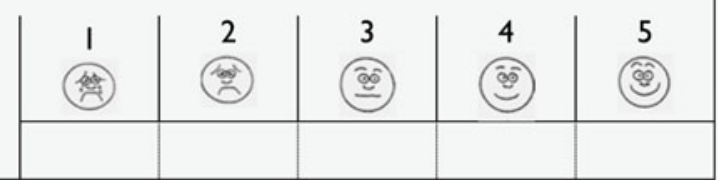

Spanish Sheet Shown to Survey Participants by Local Data Collectors

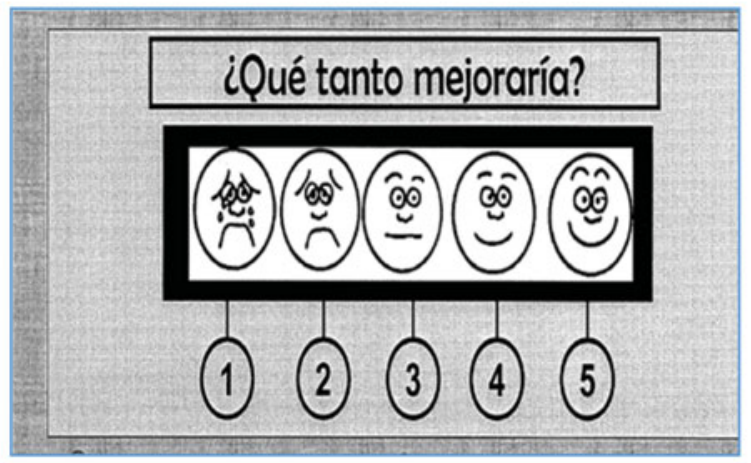

\section{English Translation}

[SHOW THEM THE NEWSET OFFACES]

5.II"Using a new scale from I-5, where now I means no improvement and 5 means extremely improved, how much do you think a smoker can improve their health by quitting?"

\section{[MARK THE RESPONSEWITH AN " $X$ " IN THIS LINE OF BOXES]}

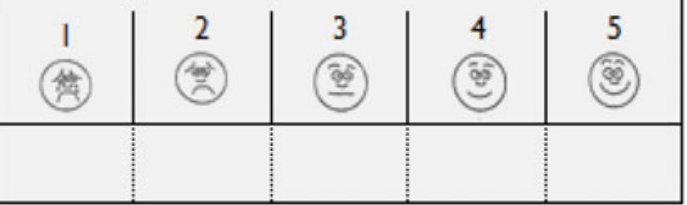

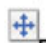

\section{Adapted from International Tobacco Control Policy Survey: Wave 1 Main Survey (Question 85) AND Global Adult Tobacco Survey (GATS) Core Questionnaire, 2008 (Questions E9-E16, E19, E20, E25, E26)}

\section{Figure 1}

Sample survey item formatting.

weekly visits to ensure that surveys had, in fact, been conducted.

TCS training mirrored data collector training, beginning with a central face to face training including development of a common intervention plan for the year, and followed by on-site refreshers and assistance with intervention launch by the core community team. Again, the central trainings provided opportunities for TCSs to share their experiences of what worked as well as new ideas for intervention implementation. The core community team conducted monthly community rounds to assess evidence of intervention implementation (e.g., PDT posters hanging in key locations, notices of marches or other awareness raising/cessation activities, hearing PDT radio PSAs/talk shows at CTC radio stations, asking community members if they had heard of PDT) and provide feedback to TCSs/site managers.

\section{Dissemination and National Networking}

In addition to joint publications and presentations described above (See Partnering for Research), several key 
lessons were learned regarding dissemination and networking.

Disseminating relevant in-country results is important for engaging broader groups beyond participating communities. For example, our data indicated that most healthcare providers were unsure whether patients wanted their advice to quit using tobacco (Prucha et al., 2015), yet $87 \%$ of tobacco users reported that this would help. Our investigators shared these results at multiple professional society and healthcare provider workshops and conferences, including trainings for public health workers through the Health Ministry. This, along with more general presentations on tobacco use and healthcare provider interventions, generated dialog and invitations for expanded presentations. Our PDT team, and particularly the site principal investigator heading the core network team, became recognized as the in-country expert on tobacco.

Beginning with partners already interested in tobacco control allows for early activities (e.g., local professional conference presentations) that ripple outward as the project becomes better known and has examples of materials and intervention models to demonstrate. For example, by the end of PDT1, a media event was held to launch a national secondhand smoke partnership with representatives from the Pan American Health Organization, the DR Pulmonary Society, DIGPRES (the DR government agency for health promotion), and PDT, which led to the PDT2 expanded focus on secondhand smoke.

Adding a core team (in PDT2) specifically focused on networking expands the partnerships and national reach (see Research Rationale/Description). For example, PDT2 convened a group of professional societies to work towards expanding tobacco control activities, and by the end of PDT2, the first DR national conference on tobacco control was held in partnership with the Internal Medicine Society, and the first national media campaign occurred with PDT PSA dissemination through the national network of CTC radio stations. Overall, national networking expanded the reach for tobacco intervention efforts in a country where this had been lacking. However, continuing efforts will be needed to maintain this capacity and build further support for broader tobacco control including legislation per the FCTC for sustainability.

\section{Mentoring}

The infrastructure of a research project provides mentoring opportunities at multiple levels to build workforce capacity for tobacco control research in communities, among research teams, and among national partners. Lessons learned regarding community level mentoring are described above (see Setting up the Research Project). An additional lesson learned was:

Mentoring expands project reach in unexpected ways. For example, PDT1 provided US MPH training for one physician investigator, with continued research mentor- ing in the DR by the US team. This co-investigator was subsequently appointed as Chair, Health Sciences Faculty Research Unit at her home university. This set the basis for advancing tobacco research in the DR through supervision of over 25 theses from medical and dentistry students on tobacco use (by both DR co-investigators), submitting locally and nationally funded grants, and implementing the first DR national surveillance of tobacco use based on the Global Adult Tobacco Survey (GATS). In addition, PDT provided pre-doctoral research experience to a US team member, leading to a doctoral dissertation on tobacco use and exposure among pregnant women in the DR (Torres et al., 2011), and MPH training to a medical student, leading to a thesis on tobacco knowledge and practices among DR healthcare providers (Prucha et al., 2015).

\section{Future Directions}

The tobacco control infrastructure developed in PDT 1 and 2 provides opportunities for expansion and continued upward ripple to engage additional communities, institutions, and organisations in tobacco cessation and secondhand smoke reductions efforts consistent with the FCTC. Such efforts will require continuing support to maintain the current momentum. Towards this end, the DR PDT co-investigators and project coordinator are faculty and advisors for our currently funded US NIH training grant (MundoComm) to engage community teams in Latin America and the Caribbean (LAC; including DR, Costa Rica, and Honduras in the current year) to develop projects addressing local maternal health issues using information communication technologies. It is possible, though not required, that one or more projects will focus on maternal tobacco use and exposure. Engagement of DR team members with colleagues in other LAC countries through MundoComm provides pathways for regional collaboration on tobacco control. Partnerships with other organizations engaged in global and regional tobacco control can further strengthen local capacity. In addition, within country, there is a need to particularly target vulnerable populations. For example, we reported higher tobacco use among illiterate groups (Ossip-Klein et al., 2008), and women and children remain especially vulnerable to secondhand smoke exposure (Dozier et al., 2014). The changing landscape of global tobacco use also requires vigilance regarding emerging products that spread to the DR or from the DR outward. Finally, continued support is needed for maintaining the tobacco surveillance initiative begun in PDT2, with results shared with key policymakers and network partners to impact policy and practice.

\section{Conclusions}

The PDT projects demonstrate the feasibility of US-LMIC (DR) partnering for trials to address tobacco use, with networking resulting in broader national in-country capacity building. The grassroots approach of working in partnership with interested communities to develop and 
test interventions that benefit the communities also provided resources, data, and models of implementation that could be used to ripple upward to expand partnerships and tobacco intervention efforts nationally.

The challenges of working cross-country and in often remote communities generated a range of lessons learned regarding the importance of partnership building, the logistics of planning and implementing a research project, the art and science of national networking for dissemination and utilization of results, and the value of mentoring at all levels.

Tobacco use and exposure remains the number one cause of premature death globally (WHO, 2011). Effectively averting the billion tobacco deaths projected for this century will require sustained focus on supporting LMIC infrastructures for tobacco control, drawing on lessons learned across partnered global trials to provide feasible and innovative approaches for addressing this modifiable public health pandemic.

\section{Acknowledgements}

The authors wish to acknowledge the funders, CTC site managers and management boards, PDT staff, community members, and the International Advisory Committee.

\section{Financial Support}

Funding for these studies was provided by the National Cancer Institute and Fogarty International Center at the US National Institutes of Health (D.J.O., grant numbers R01CA132950 and R01TWO5945; T.D. and D.J.O., grant number 1R25TW009697; E.T., HHSN261200800569P; T.D. D43TWO1282).

\section{Conflict of Interest}

None.

\section{Ethical Standards}

The authors assert that all procedures contributing to this work comply with the ethical standards of the relevant national and institutional committees on human experimentation and with the Helsinki Declaration of 1975, as revised in 2008.

\section{References}

Bilano, V., Gimmour, S., Moffiet, T., Tursan d'Espaignet, E., Stevens, G. A., Commat, Al. et al. (2015). Global trends and projections for tobacco use, 1990-2025: An analysis of smoking indicators from the WHO comprehensive information systems for tobacco control. Lancet, 385, 966-976.

Britton, J. (2015). Progress with the global tobacco epidemic. Lancet, 385, 924-926.

Central Intelligence Agency. CIA World Factbook (2015). [Online]. Retrieved on December 29. 2015: https://www.cia.gov/ library/publications/resources/the-world-factbook/geos/dr. html
Chin, N. P., Dozier, A. M., Quiñones, Z., Diaz, S., Weber, E., Almonte, $\mathrm{H}$. et al. (in press). A qualitative study of tobacco use in 8 economically disadvantaged Dominican Republic communities. Global Health Promotion.

Clinical and Translational Science Awards Consortium. (2011) Principles of Community Engagement, 2nd Edition. Community Engagement Key Function Committee Task Force on the Principlef of Community Engagement, NIH Publication No. 11-7782, Available at: http://www.atsdr.cdc.gov/ communityengagement/pdf/PCE_Report_508_FINAL.pdf

Dozier, A. M., Diaz, S., Guido, J., Quiñones de Monegro, Z., McIntosh, S., Fisher, S.G. et al. (2014). Cohort study of smoke-free homes in economically disadvantaged communities in the Dominican Republic. Revista Panamericana de Salud Publica (Journal of the Pan American Health Organization), 35, 30-37.

Dozier, A. M., Ossip, D. J., Diaz, S., Sierra, E., Quiñones, Z., Armstrong, L., Chin, N.P. et al. (2009). Health care workers in the Dominican Republic: Self-perceived role in smoking cessation. Evaluation and the Health Professions, 32,144-164 PMCID: PMC3593583.

Dozier, A. M., Ossip-Klein, D. J., Diaz, S., Chin, N. P., Sierra, E., Quiñones, Z. et al. (2006). Tobacco use in the Dominican Republic: Understanding the culture first. Tobacco Control, 15(Suppl_1), i30-i36 PMCID: PMC2563549.

Eriksen, M., Mackay, J., Schluger, N., Gomeshtapeh, F. I., \& Drope, J. (2015). The Tobacco Atlas. 5th ed. Atlanta, GA: American Cancer Society, Inc.

Israel, B. A., Schulz, A. J., Parker, E. A., \& Becker, A. B. (2001). Community-based participatory research: Recommendations for promoting a partnership approach in health research. Education for Health, 14, 182-197.

Jha, P. (2009). Avoidable global cancer deaths and total deaths from smoking. Nature Reviews Cancer, 9, 655-64.

Lando, H. A., Hipple, B. J., Muramoto, M., Klein, J. D., Prokhorov, A. V., Ossip, D. J. et al. (2010). Tobacco control and children: An international perspective. Pediatric Allergy, Immunology and Pulmonology, 23, 99-103 PMCID: PMC3281283.

McIntosh, S., Sierra, E., Dozier, A., Diaz, S., Quiñones, Z., Primack, A. et al. (2008). Ethical review issues in collaborative research between us and low-middle income country partners: A case example. Bioethics, 22, 414-422 PMCID: PMC3347871.

Ossip, D. J. (2013). The global tobacco epidemic: Public health crisis and public health opportunity. Asia-Pacific Journal of Public Health, 25(5 Suppl), 4S-6S PMID: 24092812.

Ossip, D. J., Quiñones, Z., Diaz, S., Thevenet-Morrison, K., Fisher, S., Holderness, H. et al. (2015). Tobacco cessation in economically disadvantaged Dominican Republic communities: who are the ex-users? Journal of Smoking Cessation. First Look epub. NIHMSID: NIHMS657439.

Ossip-Klein, D., Fisher, S., Diaz, S., Quinones, Z., Sierra, E., Dozier, A. et al. (2008). Tobacco use in six economically disadvantaged communities in the Dominican Republic. Nicotine and Tobacco Research, 10, 851-860 PMCID: PMC 2730378. 
Pan American Health Organization. (2012) Health in the Americas, 2012 Edition: Country Volume. Pan American Health Organization,Available at http://www.paho.org/ saludenlasamericas/index.php?option=com_docman\&task $=$ doc_view\&gid $=127 \&$ Itemid $=$

Prucha, M., Fisher, S. G., McIntosh, S., Grable, J., Holderness, H., Thevenet-Morrison, K. et al. (2015). Health care workers' knowledge, attitudes, beliefs and practices on tobacco use in seven economically disadvantaged communities in the Dominican Republic. International Journal of Environmental Research and Public Health, 12, 4060-75 PMID: 25872018.

Raw, M., Glynn, T., Munzer, A., Billo, N., Mortara, I., \& Bianco, E. (2009). Tobacco dependence and the framework convention on tobacco control. Addiction, 104, 507509.

Raw, M., Mackay, J., \& Reddy, S. (2016). Time to take tobacco dependence treatment seriously. Lancet. Jan 20, 2016. Epub ahead of print. PMID 26803442.

Riley, P. L., Jossy, R., Nkinsi, L., \& Buhi, L. (2001). The CARECDC health initiative: A model for global participatory research. American Journal of Public Health, 91, 1549-1551.

Torres, E., Guido, J., Quiñones de Monegro, Z., Diaz, S., Dozier, A., McIntosh, S. et al. (2014). Understanding sociodemographic and sociocultural factors that characterize tobacco use and cessation during pregnancy among women in the
Dominican Republic. Maternal and Child Health Journal, 18, 2275-2283 PMID: 24043558.

Torres, E., Quiñones, Z., French, L., Swanson, D. P., Guido, J., \& Ossip, D. J. (2011). Tobacco use and exposure among pregnant women in the Dominican Republic: an exploratory look into attitudes, beliefs, perceptions and practices. Nicotine and Tobacco Research, 13, 1220-1227 PMCID: PMC3223582.

Wipfli, H., Avila-Tang, E., Navas-Acien, A., Sim, S., Onicescu, G., Yuan, J. et al. (2008). Secondhand smoke exposure among women and children: Evidence from 31 countries. American Journal of Public Health, 98, 672-679 PMCID:PMC2376995.

World Bank Group. Classification of economies. (2001). [Online] Retrieved on October 9: www.worldbank.org/ data/dtatbytopic/class.htm.

World Bank Group. Data by Country. (2015). [Online]. Retrieved on December 29: http://data.worldbank. org/country/dominican-republic

World Health Organization (WHO). (2011). WHO Report on the Global Tobacco Epidemic: Warning about the Dangers of Tobacco. Available at: http://www.who.int/ tobacco/global_report/2011/en/index.html.

World Health Organization (WHO). (2015). WHO Report on the Global Tobacco Epidemic: Raising Taxes on Tobacco. Available at: http://www.who.int/tobacco/ global_report/2015/report/en/. 